Happold, F. C., Johnstone, K. I., Rogers, H. J. \& YouatT, J. B. (1954). J. gen. Microbiol. 10, 261-266.

\title{
The Isolation and Characteristics of an Organism Oxidizing Thiocyanate
}

\author{
BY F. C. HAPPOLD, K. I. JOHNSTONE, H. J. ROGERS AND \\ JEAN B. YOUATT
}

The Departments of Biochemistry and Bacteriology, University of Leeds

SUMMARY: The isolation, morphology, cultural characteristics and growth requirements of an autotroph which oxidizes thiocyanate are described. It is suggested that the organism be assigned to the genus Thiobacillus.

The oxidation of thiocyanate by bacteria was described by Happold \& Key (1937); it was not then realized that the organism was an autotroph until it was isolated in pure culture (Happold, Johnstone \& Rogers, 1952). The present paper contains a fuller description of the organism. The literature will be more comprehensively reviewed in a later paper on the metabolism of the organism.

\section{Isolation of the organism}

Material for isolation was obtained from sewage effluents and also from a well water which contained thiocyanate. The cultures were enriched by percolation, in the presence of thiocyanate, through columns designed to approximate to the conditions obtaining in filter beds. The final isolation was made by the selection of single organisms, but it was first necessary to decrease the numbers of contaminating heterotrophs. The crude cultures, although maintained in a very simple medium, appeared from plate counts for heterotrophic organisms to contain heterotrophs in numbers exceeding those of the autotroph. The basal medium used for growth of the thiocyanate organisms was: $\mathrm{Na}_{2} \mathrm{HPO}_{4}, 1 \cdot 0$ g.; $\mathrm{KH}_{2} \mathrm{PO}_{4}, 0 \cdot 6$ g.; KCNS, $0 \cdot 2$ g.; distilled water to 11 . The $\mathrm{pH}$ of the medium was $\mathbf{7 \cdot 0 - 7 \cdot 2}$. Contaminating heterotrophs were able to grow in these cultures even when the medium was prepared from water twice distilled from alkaline potassium permanganate and analytical grade reagents. Glassware was cleaned with aqua regia, and cotton-wool plugs were replaced by inverted glass beakers.

Selection of colonies from a solid medium, prepared by addition of agar to the basal medium, failed to give any cultures which oxidized thiocyanate. Flooding of the plates with ferric nitrate reagent showed that removal of thiocyanate had rarely occurred other than in areas of confluent growth. These experiments suggested that the agar, or some contaminating material, might have an inhibitory effect on the autotroph. It therefore seemed necessary to eliminate agar from the medium and to use silica gel in its place.

Silica gels were prepared by a modification of Taylor's method (Taylor, 1950) obtained from Dr W. K. Smith (Butterwick Research Laboratories, Welwyn; private communication). A $10 \%(\mathrm{w} / \mathrm{v})$ solution of sodium silicate 
was passed through a column of Amberlite 120 exchange resin. The resulting sol was stable to autoclaving and could be gelled by the addition of sterile solutions of the required salts. The amounts of salts usually added to $1 \mathrm{l}$. of the basal medium were dissolved in $125 \mathrm{ml}$. distilled water, autoclaved (15 lb./sq.in. for $15 \mathrm{~min}$.) and added to the sterile silicate solution in the proportion of 1 vol. to 3 vol. of silicate solution.

Addition to the medium of some compound which might act as an indicator of the autotrophic colonies was tried without success. There was no great $\mathrm{pH}$ change during oxidation of thiocyanate, and no indicator for the presence of thiocyanate or sulphate could be used without inhibiting growth. However, it was found that when two plates were prepared, differing only in the presence of bromthymol blue in one, and were inoculated and incubated at $22^{\circ}$ for 3-4 days, a colony form was missing from the plate containing indicator which was present on the other. This colony type was selected. Subsequent flooding of the plates with ferric nitrate reagent indicated that oxidation of thiocyanate had occurred on this plate and not on the plate containing the indicator. A culture was thus obtained which oxidized thiocyanate and would not grow, for example, on ordinary nutrient (peptone-containing) media.

Such a culture was used for the isolation of single organisms. The organisms were grown in the defined liquid medium containing thiocyanate at $22^{\circ}$ until a faint turbidity appeared. A droplet of this culture was placed on the surface of a plain $2.5 \%$ agar gel and single organisms were isolated, using dark ground illumination (Goldie, Gordon \& Johnstone, 1948; Johnstone, 1953). Eight individual organisms thus isolated were separately transferred on small cubes of agar gel to shallow layers of sterile thiocyanate medium in conical flasks, and incubated at $\mathbf{2 2}^{\circ}$. All the eight organisms were viable and utilized thiocyanate. One strain was adopted for further work. Although agar media were inhibitory to the organism, it was possible to use agar for the single cell isolation because very small blocks of agar were added to the liquid medium and the organism then grew in liquid culture.

\section{Morphology}

The organism, as may be seen from the electron micrograph ( $\mathrm{Pl} .1$ ), is a parallel-sided, round-ended $\operatorname{rod} 0 \cdot 5-1.5 \mu$. long and $c .0 \cdot 3 \mu$. wide, with a single polar flagellum. The halo-like effect has been seen to a greater or less extent on all the pictures examined. The organisms are Gram-negative, and we have seen no evidence of spore formation.

The organism is actively motile when observed by dark-ground illumination using a drop of fluid culture placed on the surface of agar or on a glass slide. Motility has been observed in freshly isolated cultures, and after 18 months of laboratory cultivation. In addition to the usual straight swimming across the field, movement in circles, both clockwise and anti-clockwise, has been observed. Some organisms rotate rapidly without progression. Finally, other organisms appear to attach themselves to the surface of glass or agar and continue to move the free end of the rod, thus describing a cone of rotation. This type of motility is said to be characteristic of polar-flagellated organisms. 


\section{Cultural characters}

In a basal liquid medium incubated aerobically at $30^{\circ}$, growth appears after 24-48 hr., depending on size and age of the inoculum. After the disappearance of the thiocyanate there is a marked tendency to clumping. In older cultures the clumped material was found to contain elementary sulphur; the addition of fresh thiocyanate to a culture which has been stored without thiocyanate for some time will often result in the separation of free sulphur. Young cultures, however, oxidize thiocyanate quantitatively to sulphate. Table 1 shows the production of ammonia and sulphate from thiocyanate. Thiocyanate was estimated colorimetrically with ferric nitrate reagent, ammonia with Nessler's reagent and sulphate turbidimetrically as $\mathrm{BaSO}_{4}$ by the addition of solid $\mathrm{BaCl}_{2}$ and comparison with freshly prepared standards. A Unicam D.G. spectrophotometer was used for the three estimations. The culture was incubated at $30^{\circ}$ and samples were withdrawn at intervals. The Table shows the disappearance of thiocyanate, the appearance of ammonia and sulphate and the calculated theoretical amounts of each.

Table 1. The production of ammonia and sulphate from thiocyanate by Thiobacillus thiocyanoxidans expressed in $\mu \mathrm{g} . / \mathrm{ml}$.

\begin{tabular}{|c|c|c|c|c|c|}
\hline $\begin{array}{l}\text { Time } \\
\text { (hr.) }\end{array}$ & $\begin{array}{c}\text { KCNS } \\
\text { loss }\end{array}$ & $\begin{array}{c}\mathrm{NH}_{3} \text { as } \mathrm{N} \\
\text { found }\end{array}$ & $\begin{array}{c}\mathrm{NH}_{3} \text { as } \mathbf{N} \\
\text { theor. }\end{array}$ & $\begin{array}{c}\mathrm{SO}_{4}^{-} \text {as } \mathrm{S} \\
\text { found }\end{array}$ & $\begin{array}{c}\mathrm{SO}_{4}^{-} \text {as } \mathrm{S} \\
\text { theor. }\end{array}$ \\
\hline 0 & 0 & $0 \cdot 1$ & 0 & 0 & 0 \\
\hline 42 & 15 & 0.55 & $2 \cdot 1$ & 2 & 4.93 \\
\hline 65 & 20 & 1.45 & $2 \cdot 9$ & 5 & $6 \cdot 6$ \\
\hline 72 & 30 & $2 \cdot 7$ & $4 \cdot 2$ & 7 & 9.9 \\
\hline 89 & 55 & $6 \cdot 4$ & 7.9 & 17 & $18 \cdot 1$ \\
\hline 96 & 82 & 9.8 & 11.8 & $24 \cdot 5$ & $27 \cdot 2$ \\
\hline 161 & 210 & $27 \cdot 5$ & 30 & 65 & $69 \cdot 3$ \\
\hline 168 & 216 & 30 & 31 & 70 & $71 \cdot 2$ \\
\hline 185 & 234 & 33 & $33 \cdot 7$ & $77 \cdot 5$ & $77 \cdot 8$ \\
\hline 192 & 240 & 33 & $34 \cdot 3$ & $77 \cdot 5$ & $79 \cdot 1$ \\
\hline
\end{tabular}

Samples were withdrawn at the times stated from a liquid medium containing KCNS $\left(240 \mu \mathrm{g} . / \mathrm{ml}\right.$.) and phosphate $\left(380 \mu \mathrm{g} . / \mathrm{ml}\right.$.) incubated at $30^{\circ}$.

Reference has already been made to the difficulty of growing the organism on the defined medium solidified with agar. That the organism can grow on agar-containing media has been clearly demonstrated (Happold \& Key, 1937; Happold et al. 1952) and it seems probable that the organism can be trained to do this. A culture was obtained by prolonged incubation on a mineral salts agar. The first growth was slow, but a subculture was found to grow and oxidize thiocyanate in 3-4 days. Some months later, when none of the original sample of agar was available, an attempt was made to grow the organism on agar samples obtained from different sources. On all of them growth then took some weeks to become visible. One sample of agar was washed by allowing plates to stand in large volumes of distilled water. When the medium prepared with this washed agar was inoculated, the rate of growth increased in successive subcultures and then maintained a growth time of three days at $30^{\circ}$. 
On thiocyanate mineral agar, the colonies were pin-point in size, circular, with entire margins and convex. In early stages they were translucent and bluish but on further incubation they became opaque and yellowish. This latter effect seemed possibly to be connected with the observed production of free sulphur in liquid cultures.

The colony form on the silica gel medium showed considerable variation, depending chiefly on the degree of moisture in the gel. The colonies were usually larger than those on agar and were flat. When the organism was first isolated, the colonies grown on silica gel were circular with entire margins and, at first, translucent, but on further incubation the outer rim of the colony became opaque. After laboratory cultivation of the strain, these types of colony were not seen and they appeared uniformly opaque on ageing. Colony size on silica gel varied from pin-point on dry surfaces to large spreading colonies on wet plates; the average colony diameter was $c .0 .5 \mathrm{~mm}$.

\section{Growth requirements}

The organism did not grow on the usual laboratory media such as peptone and yeast extract, casein digests or nutrient broth. No organic compounds have been found which will support growth in the absence of thiocyanate or improve growth in its presence. Compounds which have been tested at various concentrations include: peptone (Difco), yeast extract (Difco), glutamic acid, lactate, pyruvate, acetate, citrate, fumarate, succinate, glucose and phenol. Phenol was tested because the organism grows in its presence in gas-works liquors. Growth always occurred at normal rates in low concentrations of the organic compounds. Glutamic acid was completely inhibitory at $0.02 \%(\mathrm{w} / \mathrm{v})$. The other compounds showed some variation, but all were inhibitory at $1 \%(\mathrm{w} / \mathrm{v})$ and most showed considerable inhibition at $0 \cdot 1 \%$. In the presence of organic compounds no growth occurred without the oxidation of thiocyanate.

The organism required an oxidizable form of inorganic sulphur: thiocyanate, thiosulphate and sulphur were utilized. It seems likely, from the results of study of respiratory metabolism, that sulphide is also suitable and growth with sulphide has been observed, but owing to the production of traces of sulphur, some uncertainty remains. Briefly the experiments, which will be published later, have shown that sulphide is formed by hydrolysis of thiocyanate under conditions which do not permit oxidation. Sulphide is also oxidized by washed cell suspensions. With all these substrates except thiocyanate there was a decrease in the $\mathrm{pH}$ value of the medium during growth, due to the formation of sulphate ion. When thiocyanate was used ammonia was also produced and the $\mathrm{pH}$ change did not occur.

The thiocyanate organism, growing with thiocyanate, provides an unusual example of an organism which is able to use one simple inorganic compound as its source of energy, of nitrogen and, indirectly, of carbon. The initial step of thiocyanate metabolism is the hydrolysis of thiocyanate to sulphide, ammonia and carbon dioxide. In respiratory experiments theoretical amounts of carbon dioxide are not produced, and it appears probable that the organism 
can obtain its carbon requirements by hydrolysis of thiocyanate and subsequent absorption of carbon dioxide. This will be discussed more fully in a later paper. It will be clear from these findings that it was not possible to demonstrate directly the requirement by the organism of carbon dioxide when growing on thiocyanate, since the removal of carbon dioxide by $\mathrm{KOH}$, supposing it could be sufficiently rapid or complete, would be accompanied by the removal of the sulphide which was also essential. It was, however, possible to demonstrate the requirement of carbon dioxide for growth on thiosulphate. This was accomplished by inoculating and incubating two similar flasks of mineral salts medium containing phosphate buffer, ammonium sulphate and sodium thiosulphate. One flask was incubated in air, the other in a desiccator in the bottom of which was placed a $10 \%$ solution of $\mathrm{KOH}$. Fluted filterpapers were used to increase the area of $\mathrm{KOH}$ exposed. When the cultures, thus deprived of carbon dioxide, failed to grow over a period of ten or more times that required by the controls, they were removed and incubated in the air as a test that the inoculum had been satisfactory. Growth then occurred.

An attempt was made to test nitrate and nitrite as nitrogen sources, but it was not possible to decrease the ammonia concentration sufficiently to prevent growth in the controls. The experiment did show that nitrite was inhibitory at low concentrations (100 p.p.m.) and that some reduction of nitrate to nitrite occurred.

A requirement for phosphate was shown using media, contained in carefully washed glassware and prepared from triple distilled water, with analytical grade reagents in minimal amounts. After two subcultures no growth occurred in the control medium to which no addition was made, or in those to which $0 \cdot 2 \mu \mathrm{g} . \mathrm{P} / \mathrm{ml}$. had been added; the addition of $0 \cdot 4 \mu \mathrm{g}$. $\mathrm{P} / \mathrm{ml}$. allowed growth. High phosphate concentrations were inhibitory; growth did not occur above $1266 \mu \mathrm{g} . / \mathrm{ml}$. and the growth rate was reduced at $950 \mu \mathrm{g} . / \mathrm{ml}$. For general purposes 0.01 M-phosphate was satisfactory. It was advisable to increase the buffer concentration when using a substrate from which acid was produced, e.g. thiosulphate. Iron and magnesium were shown to be necessary by experiments similar to those described for phosphate. The effects of magnesium deficiency were more marked than those of iron deficiency.

The optimum temperature for growth is $c .30^{\circ}$, with an upper limit of $37^{\circ}$ and growth is found over the range $15-37^{\circ}$. The $\mathrm{pH}$ optimum for growth on thiocyanate, thiosulphate and sulphur was between $\mathrm{pH} \mathbf{7 \cdot 0}$ and $\mathbf{7 \cdot 2}$, although there was little variation in the rate of growth over the range $\mathrm{pH} \mathrm{6 \cdot 8-7 \cdot 6}$.

The optimum concentration of thiocyanate is $0.0025 \mathrm{M}$ if judged by the length of time which elapsed before visible growth appeared. At $0.005 \mathrm{M}$, growth appeared later but the final growth was greater. Growth also occurred at $0.01 \mathrm{~m}$ but inhibition was complete at $0.02 \mathrm{M}$.

\section{DISCUSSION}

It now seems possible to place the organism in the genus Thiobacillus and to call it $\boldsymbol{T}$. thiocyanoxidans, replacing the non-committal name, Bacterium thiocyanoxidans used hitherto. The genus Thiobacillus is characterized by the 
ability to grow with carbon dioxide as the sole source of carbon and inorganic compounds of sulphur as the source of energy. Our organism fulfils these requirements. It will grow in a medium containing only phosphate, trace metals and thiocyanate. A nitrogen source is added in the form of ammonium sulphate to obtain growth on thiosulphate or sulphur; with the latter two compounds carbon dioxide must be present in the gas phase. The organism also shows sensitivity to organic compounds.

A specimen of this organism has been lodged with the National Collection of Industrial Bacteria.

We are indebted to Dr G. Eaves for the electron micrographs and to $\mathrm{Mr}$ J. B. Kirkham for photography. One of us (J.B.Y.) held a grant from the Gas Research Council when this work was undertaken.

\section{REFERENCES}

Goldie, W., Gondon, M. \& Johnstone, K. I. (1948). Mutation in a single-cell culture of Corynebacterium diphtheriae. J. Path. Bact. 60, 369.

Happold, F. C., Johnstone, K. I. \& Rogers, H. J. (1952). An examination of Bacterium thiocyanoxidans. Nature, Lond. 169, 332.

HAPPOLd, F. C. \& KEy, A. (1937). The bacterial purification of gas-works liquors. II. The biological oxidation of ammonium thiocyanate. Biochem. J. 31, 1323.

Johnstone, K. I. (1953). Micromanipulation on an agar surface for the isolation and cultivation of single organisms. J. gen. Microbiol. 9, 293.

TaYlor, C. B. (1950). An improved method for the preparation of silica gel media for microbiological purposes. J. gen. Microbiol. 4, 285.

\section{EXPLANATION OF PLATE}

Electron micrograph of a gold-shadowed preparation of Thiobacillus thiocyanoxidans, showing the polar flagellum.

(Received 24 August 1953) 
Journal of General Microbiology, Vol. 10, No. 2

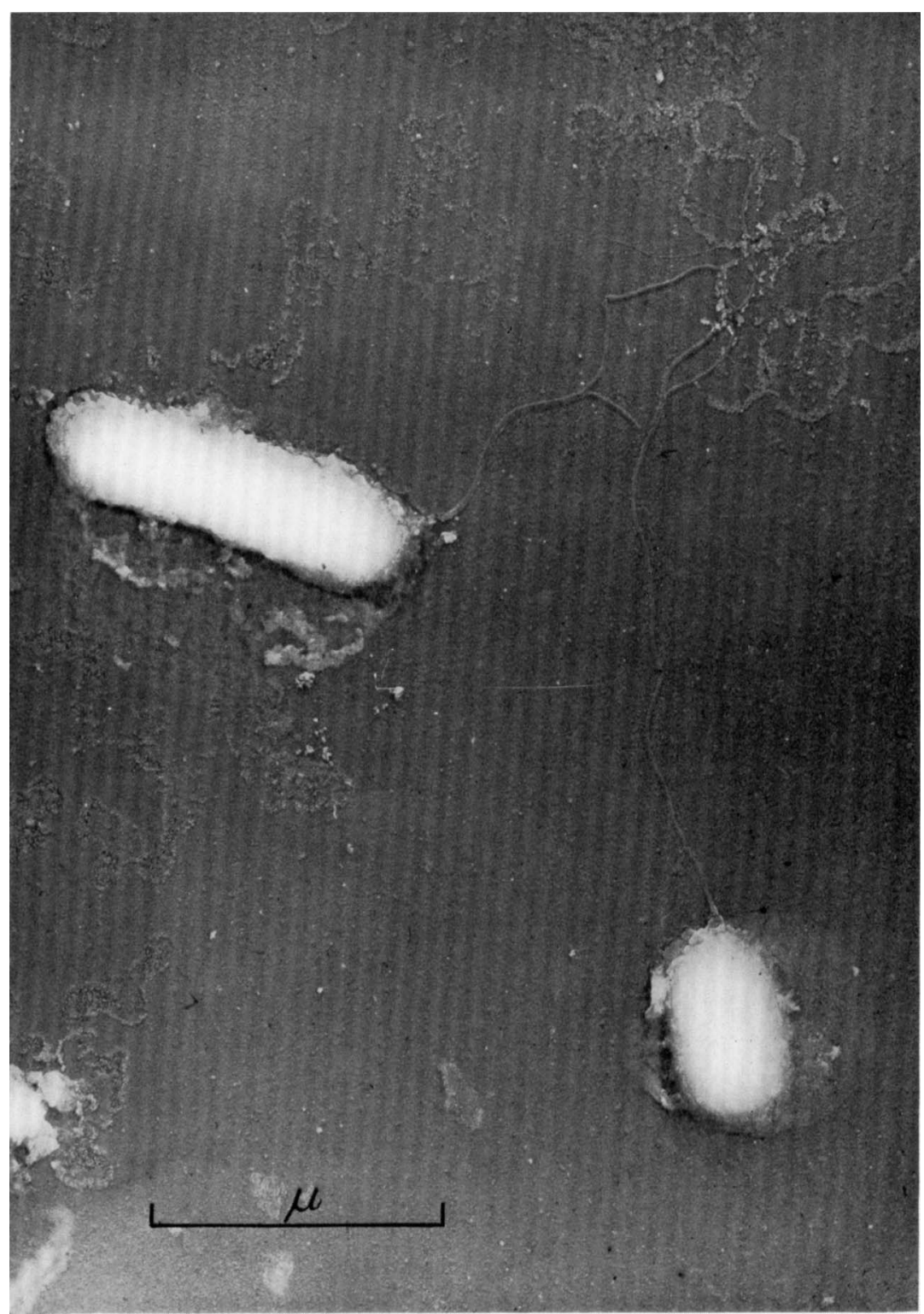

F. C. Happold, K. I. Johnstone, H. J. Rogers \& Jean B. YouatT-A bacterium oxidizing thiocyanate. Plate: 1 